Braz J Med Biol Res, September 2011, Volume 44(9) 877-882

doi: 10.1590/S0100-879X2011007500092

Involvement of catecholaminergic medullary pathways in cardiovascular responses to acute changes in circulating volume

S.L. Cravo, O.U. Lopes and G.R. Pedrino

The Brazilian Journal of Medical and Biological Research is partially financed by

\section{虽CNPq}

9)

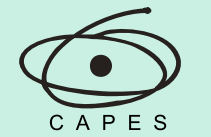

Ministério

da Educação

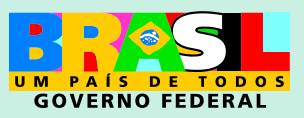

ATIPESP

\section{Institutional Sponsors}

sup?o
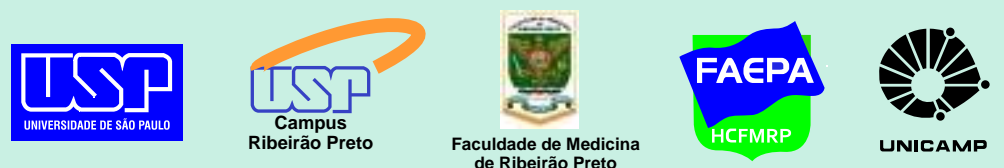

๑ SHIMADZU

Explore High - Performance MS

analitica Thermo 


\title{
Involvement of catecholaminergic medullary pathways in cardiovascular responses to acute changes in circulating volume
}

\author{
S.L. Cravo ${ }^{1}$, O.U. Lopes ${ }^{1}$ and G.R. Pedrino ${ }^{2}$ \\ 1Departamento de Fisiologia, Escola Paulista de Medicina, Universidade Federal de São Paulo, \\ São Paulo, SP, Brasil \\ 2Departamento de Ciências Fisiológicas, Universidade Federal de Goiás, Goiânia, GO, Brasil
}

\begin{abstract}
Water deprivation and hypernatremia are major challenges for water and sodium homeostasis. Cellular integrity requires maintenance of water and sodium concentration within narrow limits. This regulation is obtained through engagement of multiple mechanisms and neural pathways that regulate the volume and composition of the extracellular fluid. The purpose of this short review is to summarize the literature on central neural mechanisms underlying cardiovascular, hormonal and autonomic responses to circulating volume changes, and some of the findings obtained in the last 12 years by our laboratory. We review data on neural pathways that start with afferents in the carotid body that project to medullary relays in the nucleus tractus solitarii and caudal ventrolateral medulla, which in turn project to the median preoptic nucleus in the forebrain. We also review data suggesting that noradrenergic A1 cells in the caudal ventrolateral medulla represent an essential link in neural pathways controlling extracellular fluid volume and renal sodium excretion. Finally, recent data from our laboratory suggest that these structures may also be involved in the beneficial effects of intravenous infusion of hypertonic saline on recovery from hemorrhagic shock.
\end{abstract}

Key words: Baroreceptors; A1 noradrenergic neurons; AV3V; Renal vascular conductance; Blood pressure; Hypertonic saline

\section{Introduction}

The maintenance of a stable internal environment is, perhaps, the main objective of all physiological processes (1). Water deprivation and hypernatremia are challenges for the organism. Although daily intake and loss of water and sodium can vary widely, water and sodium concentrations must remain within narrow limits. Therefore, it is no surprise to observe the existence of multiple mechanisms and neural pathways involved in the regulation of the volume and composition of extracellular fluid (ECF). This wide variety of mechanisms ranges from renal mechanisms that alter the handling of sodium up to mechanisms that control ingestive behaviors.

Changes in body fluid osmolality such as those induced by intravenous infusion of small volumes of hypertonic saline (2-7) elicit behavioral, humoral and cardiovascular adjustments. An increase in plasma sodium concentration stimulates the ingestion of water and the release of vasoactive peptides such as vasopressin, atrial natriuretic peptide
(ANP) (2) and oxytocin (3), increases lumbar sympathetic activity and reduces renal and splanchnic nerve discharge $(4,5)$, and causes a pattern of cardiovascular adjustments characterized by transient hypertension and marked and sustained increases in renal blood flow and vascular conductance (5-7).

This integrative regulation is represented in several levels of the central nervous system. Similar to what is observed in other regulatory systems, this integrative action is organized in an increasing level of complexity along the neuroaxis.

The medulla oblongata affects several homeostatic systems, including those controlling the volume and composition of the ECF. Within the medulla oblongata, two areas are especially important for the control of ECF volume and composition: the nucleus of the tractus solitarius (NTS) and the ventrolateral medulla (VLM). Since the seminal study of Guertzenstein and colleagues (8-10), the involvement of the

Correspondence: S.L. Cravo, Departamento de Fisiologia, UNIFESP-EPM, Rua Botucatu, 862, 04023-062 São Paulo, SP, Brasil. Fax:+55-11-5573-7820. E-mail: sldcravo@fcr.epm.br

Presented at the XV Simpósio Brasileiro de Fisiologia Cardiovascular, São Paulo, SP, Brazil, February 2-5, 2011.

Received February 13, 2011. Accepted July 8, 2011. Available online July 22, 2011. Published September 16, 2011. 
VLM in ECF regulation has been extensively investigated (11-18). Twelve years ago, our laboratory began a series of studies to identify the participation of the VLM in the cardiovascular responses to acute changes of volume and composition of the ECF. The purpose of this short review is to summarize our findings and the literature concerning the central neural mechanisms underlying cardiovascular, hormonal and autonomic responses to circulating volume changes. We either expanded the ECF by infusion of isotonic solutions, or acutely increased sodium concentration through injection of minute volumes of hypertonic saline (3 $\mathrm{M} \mathrm{NaCl}$ ). The data obtained with these studies allow us to unveil a neural pathway involving carotid body afferents that transmit information to relays in the NTS and VLM, which in turn project to the median preoptic nucleus in the hypothalamus. We also demonstrated a new role of catecholaminergic medullary neurons in the cardiovascular and ingestive responses to sudden changes in ECF composition. Finally, recent data from our laboratory suggest that catecholaminergic neurons may mediate the beneficial effects of intravenous infusion of hypertonic saline on recovery from hemorrhagic shock.

\section{Role of carotid afferents in responses to ECF changes}

Several lines of evidence have suggested that, besides their well-known role in arterial blood pressure regulation, aortic and carotid afferents are also involved in cardiovascular adjustments induced by acute changes in volume or composition of the extracellular compartment (2,3,5,19-24). In a previous study, Morris and Alexander (2) showed that the ANP release after hypernatremia is severely reduced after sinoaortic denervation (SAD). Since hypernatremia in this study was induced by intravenous infusion of a small volume of hypertonic saline, ANP release could not be attributed to atrial expansion or activation of cardiopulmonary afferents. Several subsequent studies suggested that SAD also impairs the release of vasopressin, ANP and oxytocin $(2,3,19,24)$. Additional studies indicated that aortic and carotid afferents are involved in the modulation of renal sympathetic nerve activity $(5,25)$ and regulation of regional blood flow $(20,23)$ during changes of circulating volume.

Consistent with these findings, results from our laboratory have shown that carotid and aortic baroreceptor afferents are involved in cardiovascular responses to hypervolemia and hypernatremia $(20,23)$. In these studies, SAD abolished renal vasodilation, an important mechanism for the increase of sodium and water excretion, induced by volume expansion or hypertonic saline infusion, whereas bilateral vagotomy was ineffective in modifying these responses. Noteworthy is the observation that the effect of SAD was restricted to the renal territory, i.e., SAD did not block the hindlimb vasodilation induced by volume expansion. Overall, these results support the idea that integrity of the carotid and aortic afferents is essential for the cardiovascular responses that follow acute changes in ECF composition.

Several studies have shown that acute blockade of carotid and aortic afferents impairs the ability to maintain arterial pressure during hemorrhagic shock. The combined removal of baroreceptors and chemoreceptors potentiates the hypotension induced by hemorrhage in anesthetized rabbits (22) and dogs (24). This finding is predictable, and compatible with the known importance of the baroreceptor reflex in minimizing sudden changes in arterial blood pressure.

Recently, we showed that selective denervation of carotid afferents abolished the recovery of arterial blood pressure induced by infusion of hypertonic saline in rats submitted to hypotensive hemorrhage (21). In that study, carotid afferents were removed after the induction of hemorrhagic shock and mean arterial pressure was lower than $60 \mathrm{mmHg}$, i.e., below afferent threshold. Therefore, removal of carotid afferents did not modify the establishment of hypotension, but minimized the beneficial effects of hypertonic solution in the recovery phase.

It should be emphasized that the technique used in this study destroyed not only baroreceptor but also chemoreceptor afferents present in the carotid bifurcation. We subsequently examined the role of carotid body chemoreceptors in the effect of hypertonic saline, inactivating the carotid body chemoreceptors by ligation of the carotid body arteries. That study indicated that the nervous organ glomus caroticum has a prominent and determinant role in the effect of hyperosmotic saline (26). When the function of carotid body chemoreceptors was blocked, leaving all nerves in the area functional, hyperosmotic saline failed to restore arterial pressure. Thirty years ago, Gallego et al. (27) demonstrated that hypertonic solutions cause excitation of chemosensory afferents and depolarization of carotid body type I cells. Our recent studies are compatible with this early observation and suggest that the sensitivity of the chemoreceptors to tonicity has functional effects and triggers homeostatic responses.

\section{The caudal ventrolateral medulla}

The earliest evidence indicating a role of the VLM in body fluid homeostasis can be traced to the studies of Feldberg, Guertzenstein and Rocha e Silva Jr. (28-30). These investigators demonstrated that topical application of nicotine to the caudal VLM (CVLM) induced release of vasopressin, but not oxytocin, in anesthetized cats. Inhibition of neuronal activity in the CVLM also inhibited the vasopressin release induced by carotid occlusion. Combining the effects of selective blockade of sites in the rostral (RVLM) and CVLM on the cardiovascular and hormonal responses with bilateral carotid occlusion, they postulated that the RVLM is primarily related to pressor responses, whereas 
the CVLM is essential for vasopressin release.

Shortly afterward, Blessing et al. (11) demonstrated that CVLM sites similar to those described in cats regulate vasopressin release in rabbits. They also demonstrated that these sites contain catecholaminergic cells belonging to the A1 group as originally described by Dahlstroem and Fuxe (31) in the 1960s. Combining functional and neuroanatomical studies, they demonstrated that A1 cells in the CVLM directly project to the supraoptic (SON) and paraventricular nuclei (PVN) of the hypothalamus, the two main sources of vasopressin $(32,33)$.

At first it was thought that $\mathrm{A} 1$ neurons in the CVLM inhibit sympathoexcitatory neurons in the RVLM (34), but it became clear later that the CVLM neurons that mediate sympathoinhibition are GABAergic, and mainly distributed around the periambigual area (dorsally and medially to the A1 neurons). Now it is widely accepted that catecholaminergic A1 cells in the CVLM do not project to the RVLM, and that their main projections are to diencephalic nuclei involved in the control of water and salt balance $(4,12-15,17,18)$.

Neuroanatomical studies have further extended these original observations demonstrating that $\mathrm{A} 1$ noradrenergic cells receive projections from arterial baroreceptors as well as from vagal cardiopulmonary volume receptors $(35,36)$. These neurons are also reciprocally connected with hypothalamic regions known for their involvement in neuroendocrine, hydroelectrolytic, and cardiovascular regulation, including the median preoptic nucleus (MnPO), the subfornical organ (SFO), the PVN, and the SON $(32,33)$.

A functional role of $\mathrm{A} 1$ neurons in cardiovascular and humoral responses to acute reductions in central blood volume was also demonstrated in rats $(12,13,18)$. Buller et al. (12) demonstrated that Fos staining induced by hypotensive hemorrhage in neurosecretory vasopressin cells in the SON and PVN was reduced by lesions in the A1 region. Such lesions also reduce the vasopressin secretion induced by decreased circulating volume $(13,18)$.

Despite the abundance of evidence for the role of A1 noradrenergic neurons in response to reductions of blood volume, relatively little is known about their role in response to hypernatremia and volume expansion. Subcutaneous, intraperitoneal and intravenous administration of hypertonic saline increases Fos expression in the A1 group $(14,15)$, indicating neuronal activation.

We have recently demonstrated that $\mathrm{A} 1$ noradrenergic neurons are involved in the autonomic and cardiovascular responses induced by increases in plasma sodium concentration $(4,17)$. In those studies, we used anti-dopamine$\beta$-hydroxide-saporin, an immunotoxin that selectively kills dopamine- $\beta$-hydroxide ( $D \beta H$ )-containing neurons. Injection of this toxin into the CVLM caused a $62-79 \%$ loss of $A 1$ catecholaminergic neurons. The increase of renal blood flow and vascular conduction induced by intravenous hypertonic saline infusion was abolished in rats treated with anti-D $\beta \mathrm{H}$ saporin (17). Furthermore, lesion of A1 noradrenergic neurons prevented the renal sympathoinhibition induced by hypernatremia (4). Additionally, we have demonstrated that these noradrenergic cells were part of an inhibitory circuit involved in the control of $\mathrm{NaCl}$ intake induced by ANG II-dependent mechanisms (37). These studies represent the initial observation that $A 1$ noradrenergic neurons are involved in autonomic, cardiovascular and behavioral adjustments induced by changes in circulating volume.

\section{The anteroventral third ventricle region}

The preoptic-periventricular tissue surrounding the anteroventral third ventricle (AV3V) is a forebrain region with a critical role in the maintenance of fluid and electrolyte balance and cardiovascular function (7,38-44). The AV3V received its name because of its location just anteroventral $(\mathrm{AV})$ to the third ventricle $(3 \mathrm{~V})$. This area encompasses several distinct neural structures including the organum vasculosum laminae terminalis (OVLT), the ventral portion of the $\mathrm{MnPO}$, the preoptic periventricular nucleus (PPO), and the more medial aspects of the medial preoptic nucleus (MPO) $(45,46)$.

The OVLT and SFO are located in regions devoid of a blood brain barrier, and act as sensors of blood composition (47). The MnPO seems to be an integrative and relay station that receives inputs from the SFO and OVLT as well as inputs from high- and low-pressure baroreceptor pathways (48-51). The MnPO connects to regions known to be involved in body fluid homeostasis and cardiovascular regulation, such as the hypothalamic PVN and SON $(48,51$ 53). These connections appear to be important elements of central pathways involved in responses induced by changes in the body fluid volume and composition.

Several lines of evidence have demonstrated the importance of the AV3V in electrolyte balance and cardiovascular homeostasis. Intravenous infusion of hypertonic saline induces c-Fos expression in the AV3V region (54). Functional studies have demonstrated that the dipsogenic and natriuretic effects induced by hypernatremia are markedly reduced in AV3V-lesioned animals $(43,55,56)$. In addition, lesions in this region impair water intake (43) and ANP release $(39,57)$ in response to changes in circulatory volume. Consistent with these findings, our laboratory has demonstrated that electrolytic acute or chronic lesions of the AV3V prevent the renal vasodilation induced by intravenous infusion of hypertonic saline and by volume expansion $(7,38)$.

Neuroanatomical studies have shown that catecholaminergic neurons from the A1 noradrenergic group in the CVLM project strongly to the MnPO $(33,58)$. Microdialysis studies have demonstrated that electrical stimulation of $A 1$ noradrenergic groups stimulates the release of norepinephrine in the MnPO $(49,59)$. Moreover, Tanaka et al. (51) have demonstrated that electrical stimulation of the A1 noradrenergic region in the VLM can increase the discharge 
of MnPO neurons that project to the PVN. This excitatory response was blocked by the $\alpha$-adrenoceptor antagonist phentolamine, but not by the $\beta$-adrenoceptor antagonist timolol. These results suggest that the $A 1$ region acts by enhancing the activity of MnPO neurons through an activation of $\alpha$-adrenoceptors.

As mentioned before, we have recently demonstrated that the renal sympathoinhibition and vasodilation induced by hypernatremia were abolished after lesions of the A1 noradrenergic neurons in the CVLM induced with the selective toxin anti-D $\beta \mathrm{H}$-saporin $(4,17)$. Consistent with these findings, nanoinjection of norepinephine into the $\mathrm{MnPO}$, the major source of AV3V efferents, increased renal sodium excretion (60) and ANP release, whereas acute pharmacological blockade of a1-adrenoceptors in the AV3V reduced the ANP release induced by blood volume expansion (40). Therefore, we hypothesized that noradrenergic neurotransmission from the A1 noradrenergic group to the MnPO may be involved in the cardiovascular responses to hypernatremia. To confirm this hypothesis, we studied the effects of nanoinjection of adrenergic antagonists into the MnPO and observed that blockade of $\alpha 1$ - and $\alpha 2$-adrenoceptors in the MnPO prevented the renal vasodilation induced by intravenous infusion of hypertonic saline (44). Moreover, $\alpha 1$-adrenoceptors seem to be important not only in the initiation, but also in the maintenance of this hypernatremiainduced response (44).

Overall, these recent lines of evidence support the view that $A 1$ neurons in the CVLM are activated upon stimulation of peripheral carotid afferents (baroreceptor and chemoreceptors), engaging efferent pathways to hypothalamic regions, such as the $\mathrm{MnPO}$, that regulate the endocrine, autonomic, behavioral, and cardiovascular responses that maintain body fluid homeostasis (Figure 1). Since this pathway is important for sympathetic responses to changes of circulating volume, dysfunction of these neurons may result in inadequate function of the renal sympathetic nerves, and this may contribute to the pathophysiology of hypertension, congestive heart failure and cirrhosis.

\section{Acknowledgments}

Studies by the authors' laboratories were supported by CAPES (\#BEX1380/07-9) and CNPq (\#477832/2010-5).

\section{References}

1. Cannon WB. Organization for physiological homeostasis. Physiol Rev 1929; 9: 399-431.

2. Morris M, Alexander N. Baroreceptor influences on plasma atrial natriuretic peptide (ANP): sinoaortic denervation reduces basal levels and the response to an osmotic challenge. Endocrinology 1988; 122: 373-375. 
3. Morris M, Alexander N. Baroreceptor influences on oxytocin and vasopressin secretion. Hypertension 1989; 13: 110114.

4. Pedrino GR, Rosa DA, Korim WS, Cravo SL. Renal sympathoinhibition induced by hypernatremia: involvement of A1 noradrenergic neurons. Auton Neurosci 2008; 142: 55-63.

5. Weiss ML, Claassen DE, Hirai T, Kenney MJ. Nonuniform sympathetic nerve responses to intravenous hypertonic saline infusion. J Auton Nerv Syst 1996; 57: 109-115.

6. Fujita T, Matsuda Y, Shibamoto T, Uematsu H, Sawano F, Koyama S. Effect of hypertonic saline infusion on renal vascular resistance in anesthetized dogs. Jpn J Physiol 1991; 41: 653-663.

7. Pedrino GR, Nakagawa Sera CT, Cravo SL, Colombari DS. Anteroventral third ventricle lesions impair cardiovascular responses to intravenous hypertonic saline infusion. Auton Neurosci 2005; 117: 9-16.

8. Guertzenstein PG, Silver A. Fall in blood pressure produced from discrete regions of the ventral surface of the medulla by glycine and lesions. J Physiol 1974; 242: 489-503.

9. Guertzenstein PG. Blood pressure effects obtained by drugs applied to the ventral surface of the brain stem. J Physiol 1973; 229: 395-408.

10. Feldberg W, Guertzenstein PG. A vasodepressor effect of pentobarbitone sodium. J Physiol 1972; 224: 83-103.

11. Blessing WW, Sved AF, Reis DJ. Destruction of noradrenergic neurons in rabbit brainstem elevates plasma vasopressin, causing hypertension. Science 1982; 217: 661-663.

12. Buller KM, Smith DW, Day TA. Differential recruitment of hypothalamic neuroendocrine and ventrolateral medulla catecholamine cells by non-hypotensive and hypotensive hemorrhages. Brain Res 1999; 834: 42-54.

13. Head GA, Quail AW, Woods RL. Lesions of A1 noradrenergic cells affect AVP release and heart rate during hemorrhage. Am J Physiol 1987; 253: H1012-H1017.

14. Hochstenbach SL, Ciriello J. Plasma hypernatremia induces c-fos activity in medullary catecholaminergic neurons. Brain Res 1995; 674: 46-54.

15. Howe BM, Bruno SB, Higgs KA, Stigers RL, Cunningham JT. FosB expression in the central nervous system following isotonic volume expansion in unanesthetized rats. Exp Neurol 2004; 187: 190-198.

16. Pedrino GR, Ferreira-Neto ML, Carillo BA, Cravo SL. Catecholaminergic neurons of the caudal ventrolateral medulla mediate renal sympathoinhibiton induced by hypertonic saline infusion. Faseb Journal 2007; 21: A513.

17. Pedrino GR, Maurino I, de Almeida Colombari DS, Cravo SL. Role of catecholaminergic neurones of the caudal ventrolateral medulla in cardiovascular responses induced by acute changes in circulating volume in rats. Exp Physiol 2006; 91 : 995-1005.

18. Smith DW, Sibbald JR, Khanna S, Day TA. Rat vasopressin cell responses to simulated hemorrhage: stimulus-dependent role for A1 noradrenergic neurons. Am J Physiol 1995; 268: R1336-R1342.

19. Antunes-Rodrigues J, Machado BH, Andrade HA, Mauad $H$, Ramalho MJ, Reis LC, et al. Carotid-aortic and renal baroreceptors mediate the atrial natriuretic peptide release induced by blood volume expansion. Proc Natl Acad Sci U S A 1992; 89: 6828-6831.

20. Colombari DS, Colombari E, Lopes OU, Cravo SL. Afferent pathways in cardiovascular adjustments induced by volume expansion in anesthetized rats. Am J Physiol Regul Integr Comp Physiol 2000; 279: R884-R890.

21. de Almeida Costa EF, Pedrino GR, Lopes OU, Cravo SL. Afferent pathways involved in cardiovascular adjustments induced by hypertonic saline resuscitation in rats submitted to hemorrhagic shock. Shock 2009; 32: 190-193.

22. Hosomi H, Katsuda S, Morita H, Nishida Y, Koyama S. Interactions among reflex compensatory systems for posthemorrhage hypotension. Am J Physiol 1986; 250: H944-H953.

23. Sera CTN, Colombari DS, Cravo SL. Afferent pathways involved in the renal vasodilation induced by hypertonic saline. Hypertension 1999; 33: 1315 (Abstract).

24. Thrasher TN, Keil LC. Arterial baroreceptors control blood pressure and vasopressin responses to hemorrhage in conscious dogs. Am J Physiol 1998; 275: R1843-R1857.

25. Blessing WW, Willoughby JO. Depressor neurons in rabbit caudal medulla do not transmit the baroreceptor-vasomotor reflex. Am J Physiol 1987; 253: H777-H786.

26. Pedrino GR, Rossi MV, Schoorlemmer GH, Lopes OU, Cravo SL. Cardiovascular adjustments induced by hypertonic saline in hemorrhagic rats: Involvement of carotid body chemoreceptors. Auton Neurosci 2011; 160: 37-41.

27. Gallego R, Eyzaguirre C, Monti-Bloch L. Thermal and osmotic responses of arterial receptors. J Neurophysiol 1979; 42: 665-680.

28. Feldberg W, Rocha e Silva M Jr. Vasopressin release produced in anaesthetized cats by antagonists of gammaaminobutyric acid and glycine. Br J Pharmacol 1978; 62: 99-106.

29. Feldberg W, Rocha e Silva M Jr. GABA and glycine inhibit vasopressin release to carotid occlusion [proceedings]. $J$ Physiol 1979; 289: 43P-44P.

30. Feldberg W, Guertzenstein PG, Rocha e Silva M Jr. Vasopressin release by nicotine: the site of action. $\mathrm{Br} J$ Pharmacol 1975; 54: 463-474.

31. Dahlstroem A, Fuxe K. Evidence for the existence of monoamine-containing neurons in the central nervous system. I. Demonstration of monoamines in the cell bodies of brain stem neurons. Acta Physiol Scand Suppl 1964; 62: 1-55.

32. Saper CB, Reis DJ, Joh T. Medullary catecholamine inputs to the anteroventral third ventricular cardiovascular regulatory region in the rat. Neurosci Lett 1983; 42: 285-291.

33. Tucker DC, Saper CB, Ruggiero DA, Reis DJ. Organization of central adrenergic pathways: I. Relationships of ventrolateral medullary projections to the hypothalamus and spinal cord. J Comp Neurol 1987; 259: 591-603.

34. Granata AR, Numao Y, Kumada M, Reis DJ. A1 noradrenergic neurons tonically inhibit sympathoexcitatory neurons of C1 area in rat brainstem. Brain Res 1986; 377: 127-146.

35. Day TA, Sibbald JR. Involvement of the A1 cell group in baroreceptor inhibition of neurosecretory vasopressin cells. Neurosci Lett 1990; 113: 156-162.

36. Day TA, Sibbald JR, Smith DW. A1 neurons and excitatory amino acid receptors in rat caudal medulla mediate vagal excitation of supraoptic vasopressin cells. Brain Res 1992; 594: 244-252.

37. Colombari DS, Pedrino GR, Freiria-Oliveira AH, Korim WS, Maurino IC, Cravo SL. Lesions of medullary catecholaminergic neurons increase salt intake in rats. Brain Res Bull 2008; 76: 572-578.

38. Colombari DS, Cravo SL. Effects of acute AV3V lesions on renal and hindlimb vasodilation induced by volume expan- 
sion. Hypertension 1999; 34: 762-767.

39. Rauch AL, Callahan MF, Buckalew VM Jr, Morris M. Regulation of plasma atrial natriuretic peptide by the central nervous system. Am J Physiol 1990; 258: R531-R535.

40. Antunes-Rodrigues J, Marubayashi U, Favaretto AL, Gutkowska J, McCann SM. Essential role of hypothalamic muscarinic and alpha-adrenergic receptors in atrial natriuretic peptide release induced by blood volume expansion. Proc Natl Acad Sci U S A 1993; 90: 10240-10244.

41. May CN, McAllen RM, McKinley MJ. Renal nerve inhibition by central $\mathrm{NaCl}$ and ANG II is abolished by lesions of the lamina terminalis. Am J Physiol Regul Integr Comp Physiol 2000; 279: R1827-R1833.

42. Bealer SL. Sodium excretion following lesions of preoptic recess periventricular tissue in the rat. Am J Physiol 1983; 244: R815-R822.

43. Buggy J, Johnson AK. Anteroventral third ventricle periventricular ablation: temporary adipsia and persisting thirst deficits. Neurosci Lett 1977; 5: 177-182.

44. Pedrino GR, Monaco LR, Cravo SL. Renal vasodilation induced by hypernatraemia: role of alpha-adrenoceptors in the median preoptic nucleus. Clin Exp Pharmacol Physiol 2009; 36: e83-e89.

45. Johnson AK, Edwards GL. Central projections of osmotic and hypovolaemic signals in homeostatic thirst. In: Ramsay DJ, Booth DA (Editors), Thirst: physiological and psychological - aspects. Berlin: Springer-Verlarg; 1991. p 149-175.

46. Johnson AK, Cunningham JT, Thunhorst RL. Integrative role of the lamina terminalis in the regulation of cardiovascular and body fluid homeostasis. Clin Exp Pharmacol Physiol 1996; 23: 183-191.

47. Bourque CW, Oliet SH, Richard D. Osmoreceptors, osmoreception, and osmoregulation. Front Neuroendocrinol 1994; 15: 231-274.

48. Chiba T, Murata Y. Afferent and efferent connections of the medial preoptic area in the rat: a WGA-HRP study. Brain Res Bull 1985; 14: 261-272.

49. Fernandez-Galaz C, Dyer RG, Herbison AE. Analysis of brainstem $\mathrm{A} 1$ and $\mathrm{A} 2$ noradrenergic inputs to the preoptic area using microdialysis in the rat. Brain Res 1994; 636: 227-232.
50. Saper CB, Levisohn D. Afferent connections of the median preoptic nucleus in the rat: anatomical evidence for a cardiovascular integrative mechanism in the anteroventral third ventricular (AV3V) region. Brain Res 1983; 288: 21-31.

51. Tanaka J, Nishimura J, Kimura F, Nomura M. Noradrenergic excitatory inputs to median preoptic neurones in rats. Neuroreport 1992; 3: 946-948.

52. McKinley MJ, Mathai ML, McAllen RM, McClear RC, Miselis RR, Pennington GL, et al. Vasopressin secretion: osmotic and hormonal regulation by the lamina terminalis. $J \mathrm{Neu}$ roendocrinol 2004; 16: 340-347.

53. Weiss ML, Hatton GI. Collateral input to the paraventricular and supraoptic nuclei in rat. I. Afferents from the subfornical organ and the anteroventral third ventricle region. Brain Res Bull 1990; 24: 231-238.

54. Hochstenbach SL, Ciriello J. Effect of lesions of forebrain circumventricular organs on c-fos expression in the central nervous system to plasma hypernatremia. Brain Res 1996; 713: 17-28.

55. Johnson AK, Buggy J. Periventricular preoptic-hypothalamus is vital for thirst and normal water economy. Am J Physiol 1978; 234: R122-R129.

56. McKinley MJ, Lichardus B, McDougall JG, Weisinger RS. Periventricular lesions block natriuresis to hypertonic but not isotonic $\mathrm{NaCl}$ loads. Am J Physiol 1992; 262: F98-F107.

57. Antunes-Rodrigues J, Ramalho MJ, Reis LC, Menani JV, Turrin MQ, Gutkowska J, et al. Lesions of the hypothalamus and pituitary inhibit volume-expansion-induced release of atrial natriuretic peptide. Proc Natl Acad Sci U S A 1991; 88: 2956-2960

58. Blessing WW, Jaeger CB, Ruggiero DA, Reis DJ. Hypothalamic projections of medullary catecholamine neurons in the rabbit: a combined catecholamine fluorescence and HRP transport study. Brain Res Bull 1982; 9: 279-286.

59. Herbison AE, Heavens RP, Dyer RG. Oestrogen modulation of excitatory $A 1$ noradrenergic input to rat medial preoptic gamma aminobutyric acid neurones demonstrated by microdialysis. Neuroendocrinology 1990; 52: 161-168.

60. Morris M, McCann SM, Orias R. Role of transmitters in mediating hypothalamic control of electrolyte excretion. Can J Physiol Pharmacol 1977; 55: 1143-1154. 